\title{
Metabolic markers in Ossabaw pigs fed high fat diets enriched in regular or low a-linolenic acid soy oil
}

Ramesh B Potu, Hang Lu, Olayiwola Adeola and Kolapo M Ajuwon*

\begin{abstract}
Background: Soy oil is a major vegetable oil consumed in the US. A recently developed soybean variety produces oil with a lower concentration of a-linolenic acid, hence a higher $(n-6) /(n-3)$ ratio, than regular soy oil. The study was conducted to determine the metabolic impact of the low a-linolenic acid containing soy oil.
\end{abstract}

Methods: Ossabaw pigs were fed diets supplemented with either 13\% regular soybean oil (SBO), or 13\% of the low a-linolenic soybean oil (LLO) or a control diet (CON) without extra oil supplementation, for 8 weeks.

Results: Serum and adipose tissue a-linolenic acid concentration was higher in pigs fed the SBO diet than those on the CON and LLO diets. In the serum, the concentration of saturated fatty acids (SFA) was lower in the LLO group than in CON and SBO groups polyunsaturated fatty acid (PUFA) concentration was higher in the LLO group compared to CON and SBO groups. Glucose, insulin, triglycerides and LDL-cholesterol were higher in pigs fed the SBO diet than those fed the CON and LLO diets. HDL-cholesterol was lower in pigs on the SBO diet than those on the CON and LLO diets. Pigs fed SBO and LLO diets had lower CRP concentration than those on the CON diet. Adipose tissue expression of Interleukin 6 (IL-6) was higher in the SBO and LLO diets than the CON. Expression of ECM genes, COLVIA and fibronectin, was significantly reduced in the SBO diet relative to the CON and LLO diets whereas expression of inflammation-related genes, cluster of differentiation 68 (CD68) and monocyte chemoattractant protein 1 (MCP-1), was not different across treatments.

Conclusions: Results suggest that lowering the content of a-linolenic acid in the context of a high fat diet could lead to mitigation of development of hyperinsulinemia and dyslipidemia without significant effects on adipose tissue inflammation.

Keywords: Linolenic, Soy bean oil, Pigs, Obesity, Metabolic syndrome

\section{Background}

Obesity is a state of chronic low-grade inflammation that is associated with insulin resistance, hyperlipidemia and cardiometabolic diseases [1,2]. Several studies have linked consumption of diets high in oils to an increased incidence of obesity [3-5]. In contrast, consumption of diets rich in unsaturated fatty acids such as soy oil, with its high content of linoleic and $\alpha$-linolenic acids, is beneficial in reducing inflammation and serum lipid concentrations $[6,7]$. Consumption of polyunsaturated fatty acids is also associated with reduced cardiovascular disease risk [8]. Soy oil is

\footnotetext{
*Correspondence: kajuwon@purdue.edu

Department of Animal Sciences, Purdue University, West Lafayette, IN 47907,
} USA

\section{Biomed Central}

the vegetable oil consumed in the largest amounts in American diets [9]. However, $\alpha$-linolenic acid is rapidly degraded during processing and in storage due to its highly unsaturated structure. It oxidizes twice as quickly as linoleic acid [C18:2(n-6)] under stable conditions [10]. Therefore, a low $\alpha$-linolenic acid soy oil was developed to improve the shelf life of the oil. The low $\alpha$-linolenic acid oil thus eliminates the requirement for hydrogenation of soy oil due to the overall reduction in the content of unsaturated bonds. The low $\alpha$-linolenic oil contains less than $3 \% \alpha$-linolenic acid versus the $7 \%$ in conventional soy oil [11]. Due to the alteration in the fatty acid composition of the low $\alpha$-linolenic acid soy oil, it is important to study the effect of its consumption on major metabolic markers 
with respect to lipid metabolism, insulin sensitivity and inflammatory status. Therefore, the main objective of this work was to compare the metabolic and inflammatory impact of consumption of low $\alpha$-linolenic soy oil vs. regular soy oil.

\section{Methods}

\section{Animals and diets}

The Purdue Animal Care and Use Committee (PACUC) approved all procedures on care and use of pigs described in this study. Twelve female Ossabaw pigs at 3 months of age were divided, four per group, into the three dietary treatments; Control diet (CON) with no extra oil addition, a high fat diet with $13 \%$ regular soybean oil diet (SBO) (from a local retail store), and a high fat diet with 13\% low $\alpha$-linolenic soybean oil diet (LLO) (Zeeland food services, Zeeland, MI). The initial weights of the pigs were 13.9, 13.7 and $14.2 \mathrm{~kg}$ for the CON, SBO and LLO treatments, respectively. The nutrient composition of experimental diets is presented in Table 1 . The fatty acid composition of the regular soy oil and the low $\alpha$-linolenic oil are also presented in Table 2. The fatty acid composition of diets is presented in Table 3. Pigs were penned individually at the Purdue small animal housing facility and were fed ad libitum for $8 \mathrm{wks}$. The total fat content of the soy oil diets (SBO and LLO) was increased to $19.7 \%$ by the addition of $13 \%$ of respective soy oils to a basal diet (5L80, Lab Diet, St. Louis, MO). The soy oil diets also contained $2 \%$ cholesterol and $0.67 \%$ sodium cholate by weight. Pigs were killed at the end of the study with intramuscular injection of atropine, tiletamine-zolazepam, and xylazine followed by pneumothorax and cardiectomy.

Table 1 Analyzed diet composition

\begin{tabular}{|c|c|c|c|}
\hline \multirow[t]{2}{*}{ Ingredient (\%) } & \multicolumn{3}{|c|}{ Treatment $^{1}$} \\
\hline & CON & SBO & LLO \\
\hline \multicolumn{4}{|l|}{ Composition $^{*}$} \\
\hline Carbohydrates & 64.5 & 45.9 & 45.9 \\
\hline$\overline{\text { Fat }^{2}}$ & 3.9 & 19.7 & 19.7 \\
\hline Protein & 15.4 & 15.8 & 15.8 \\
\hline Cholesterol & 0 & 2 & 2 \\
\hline Sodium Cholate & 0 & 0.67 & 0.67 \\
\hline Corn Syrup & 0 & 5 & 5 \\
\hline Minerals \& Vitamins & 6.2 & 6.2 & 6.2 \\
\hline \multicolumn{4}{|c|}{ Amount of energy supplied } \\
\hline Carbohydrates (\%) & 71.0 & 41.1 & 41.12 \\
\hline Fat (\%) & 10.5 & 40.9 & 40.9 \\
\hline Protein (\%) & 18.5 & 18.0 & 18.0 \\
\hline \multicolumn{4}{|c|}{$\begin{array}{l}{ }^{1} \text { CON, control diet with no added oil; SBO, metabolic syndrome diet }+13 \% \\
\text { soybean oil; LLO, metabolic syndrome diet }+13 \% \text { low a-linolenic soybean oil. } \\
{ }^{2} \text { In addition to the soy oil, other ingredients that supplied fat include corn, } \\
\text { soybean meal, alfalfa meal and wheat middlings. } \\
{ }^{*} \text { Proximate composition of diets. }\end{array}$} \\
\hline
\end{tabular}

Table 2 Fatty acid composition of the different soy oils

\begin{tabular}{lcc}
\hline Fatty acid (\%) & SBO & LLO \\
\hline Myristic acid & 0.07 & 0.07 \\
\hline Palmitic acid & 10.4 & 9.7 \\
\hline Stearic acid & 4.1 & 4.6 \\
\hline Oleic acid & 21.4 & 22.2 \\
\hline Linoleic acid & 54.8 & 60.1 \\
\hline a-Linolenic acid & 7.5 & 1.5 \\
\hline Arachidonic acid & $\mathrm{ND}$ & $\mathrm{ND}$ \\
\hline Eicosapentaenoic acid & $\mathrm{ND}$ & $\mathrm{ND}$ \\
\hline Docosahexaenoic acid & $\mathrm{ND}$ & $\mathrm{ND}$ \\
\hline Omega 6 (n6) & 54.8 & 60.1 \\
\hline Omega 3 (n3) & 7.5 & 1.5 \\
\hline Omega 6: Omega 3 (n6/n3) & 7.3 & 40.1 \\
\hline
\end{tabular}

ND - not detected.

SBO, metabolic syndrome diet $+13 \%$ soybean oil; LLO, metabolic syndrome diet $+13 \%$ low $a$-linolenic soybean oil.

\section{RNA isolation and CDNA synthesis}

Isolated RNA was dissolved in nuclease free water (Ambion, Austin, TX) and concentrations were determined using a Nanodrop machine (Thermo Scientific, Waltham, MA). RNA samples were subjected to electrophoresis on a $1 \%$ agarose gel to check for RNA integrity. One microgram of total RNA was reverse transcribed with the MMLV reverse transcriptase (Promega, Madison, WI).

Table 3 Fatty acid composition of diets

\begin{tabular}{|c|c|c|c|}
\hline \multirow[t]{2}{*}{ Fatty acid (\%) } & \multicolumn{3}{|c|}{ Treatment $^{1}$} \\
\hline & CON & SBO & LLO \\
\hline Myristic acid & 0.30 & 0.08 & 0.10 \\
\hline Palmitic acid & 14.08 & 10.93 & 10.55 \\
\hline Palmitoleic acid & 0.30 & 0.10 & 0.13 \\
\hline Stearic acid & 4.50 & 3.95 & 4.64 \\
\hline Oleic acid & 21.95 & 19.71 & 21.27 \\
\hline Vaccenic acid & 1.18 & 1.30 & 1.25 \\
\hline Linoleic acid & 45.51 & 53.59 & 56.90 \\
\hline cis9, trans $11 \mathrm{CLA}$ & $\mathrm{ND}^{2}$ & 0.23 & 0.09 \\
\hline trans 10 , cis $12 \mathrm{CLA}$ & ND & ND & ND \\
\hline a-Linolenic acid & 3.68 & 7.14 & 1.95 \\
\hline Arachidonic acid & ND & ND & ND \\
\hline Eicosapentaenoic acid & ND & ND & $\mathrm{ND}$ \\
\hline Docosahexaenoic acid & ND & ND & ND \\
\hline Omega 6 (n6) & 45.51 & 53.82 & 56.99 \\
\hline Omega 3 (n3) & 3.68 & 7.14 & 1.95 \\
\hline Omega 6: Omega 3 (n6/n3) & 12.4 & 7.5 & 29.2 \\
\hline
\end{tabular}

${ }^{1} \mathrm{CON}$, control diet with no added oil; SBO, metabolic syndrome diet $+13 \%$ soybean oil; LLO, metabolic syndrome diet $+13 \%$ low a-linolenic soybean oil. ${ }^{2} \mathrm{ND}$ - not detected. 


\section{Real-time PCR analysis}

Real-time quantitative PCR was performed on a MyiQ real-time PCR detection system (Bio-Rad, Hercules, CA) using the SYBR RT-PCR mix (SABiosciences, Frederic, $\mathrm{MD})$. The relative abundance of mRNA of the different genes was determined from the threshold cycle $(\mathrm{Ct})$ for the respective genes after normalization with $18 \mathrm{~S}$ which served as the internal control [12]. Primers used for RTPCR are listed in Table 4.

\section{Western blot analysis}

Adipose tissue was homogenized in RIPA lysis buffer (50 mmol/l Trizma-HCl ( $\mathrm{pH} 7.4), 15 \mathrm{mmol} / \mathrm{l} \mathrm{NaCl}$, $0.25 \%$ deoxycholic acid, $0.1 \%$ Triton $\mathrm{X}, 10 \mathrm{mmol} / \mathrm{l}$ EDTA, $1 \mathrm{mmol} / \mathrm{l} \mathrm{Na}_{2} \mathrm{VO}_{3}$ and protease inhibitor cocktail (Sigma-Aldrich). Homogenates were centrifuged at $10,000 \times \mathrm{g}$ for $10 \mathrm{~min}$ at $4^{\circ} \mathrm{C}$ to remove fat debris. Protein concentrations in homogenates were determined with the bicinchoninic acid (BCA) protein assay kit (Thermo Scientific, Waltham, MA). Protein samples were resolved on $10 \%$ SDS-PAGE gel and were transferred to a $0.2 \mu \mathrm{m}$ nitrocellulose membrane using the semi-dry method (Bio-Rad, Hercules, CA). Membranes were blocked in $5 \%$ bovine serum albumin (BSA) in TBS (50 mmol/L Tris. $\mathrm{HCl}, \mathrm{pH}$ 7.4, $150 \mathrm{mmol} / \mathrm{L} \mathrm{NaCl}$, $0.1 \%$ Tween 20). Immunoblotting for adiponectin was performed overnight at $4^{\circ} \mathrm{C}$ using a rabbit anti-porcine adiponectin antibody (kindly provided by Xeno Diagnostics, Indianapolis, IN) at a dilution of 1:1000. Membranes were stripped and reprobed with a rabbit anti- $\beta$-actin antibody (Cell Signaling Technologies, Danvers, MA) at a dilution of 1:1000. Blots were then incubated with a goat anti-rabbit secondary antibody conjugated to horseradish peroxidase (Cell Signaling Technologies, Danvers, MA) at a dilution of 1:20,000. Chemiluminescent signals from membranes were captured by autoradiography using the Immobilon (Millipore, Billerica, MA) chemilumniscent reagent. Densitometric analysis of western blots was performed using Kodak EDAS290 imaging system (Kodak, New Haven, CT).

\section{Determination of serum metabolites}

Blood was collected from animals via the jugular vein after an overnight fast (8-10 hours). Whole blood was centrifuged at $4^{\circ} \mathrm{C}$ at $1500 \times \mathrm{g}$ for 15 minutes for collection of serum. Serum blood glucose concentration was determined with an automatic glucometer (Freestyle, Alameda, CA). Serum free fatty acid was determined using the free fatty acids half micro test kit (Roche Diagnostics, Indianapolis, IN). Serum triglyceride was determined with the triglyceride determination kit (Sigma Aldrich, St Louis, MO). Serum cholesterol concentration was determined using the Amplex Red cholesterol assay reagent (Invitrogen, Carlsbad, CA). High density lipoprotein (HDL) was separated for analysis from serum using an HDL kit (Pointe Scientific Inc., Canton, MI). All assays were performed according to instructions from the manufacturers.

\section{Insulin and C-reactive protein ELISA}

Determination of serum insulin was conducted using the Mercodia porcine insulin ELISA kit (Mercodia, Uppsala, Sweden) and C-reactive protein (CRP) was determined using CRP kit (Immunology Consultants lab, Portland, OR) according to the manufacturer's instructions.

\section{Tissue and serum fatty acids analysis}

The modified procedure of Folch et al. [13] was used for total lipids extraction. Subcutaneous fat and serum samples were extracted in a 2:1 ( $\mathrm{vol} / \mathrm{vol})$ chloroform: methanol organic solvent mixture [13]. Extracted fatty acids were dissolved in hexane for gas chromatographic analysis.

\section{Gas chromatography}

Fatty acid methyl esters were quantified on a gas chromatography system (Varian 3900), using a CP wax 52 CB capillary column (Varian Inc., Palo Alto, CA). A Supelco PUFA-2 Component FAME Mix was used as the standard (Sigma-Aldrich, St. Louis, MO). Chromatographic profiles were evaluated for main fatty acid peak strengths.

\section{Table 4 List of primers}

\begin{tabular}{|c|c|c|}
\hline Gene & Forward & Reverse \\
\hline 185 & 5'-ATC CCT GAG AAG TTC CAG CA-3' & 5'-CCT CCT GGT GAG GTC GAT GT-3' \\
\hline$T N F a$ & 5'-CCA CCA ACG TाT TCC TCA CT-3' & 5'-CCC AGG TAG ATG GGT TCG TA-3' \\
\hline$\overline{I L 6}$ & 5'-TTC ACC TCT CCG GAC AAA AC-3' & $5^{\prime}$-TCT GCC AGT ACC TCC TTG CT-3' \\
\hline Adiponectin & 5'-TGG AGA AAG CGC CTA TGT CT-3' & $5^{\prime}-\pi T T$ GCC AGT GGT GAC ATC AT-3' \\
\hline COL1A & $5^{\prime}$-GAC CGA GAC GTG TGG AAA C-3' & 5'-CGC TGG GAC AGT TCT TGA TT-3' \\
\hline$\overline{C O L V I A}$ & 5'-CGA CAT TGT GTT CCT GTT GG-3' & 5'-TTC GTA AAC CGT GTC CAC AA-3' \\
\hline Fibronectin & $5^{\prime}$-AGC TGG AGG ACC AAG ACT GA-3' & 5'-TGC CAT GAT ACC AAC AAG GA-3' \\
\hline$\overline{C D 68}$ & 5'-ACG TTG GCT GTG CTC TTC TT-3' & 5'-CTG GTG GTG GTA GCA GGA TT-3' \\
\hline$\overline{M C P 1}$ & 5'-CAC CAG CAG CAA GTG TCC TA-3' & 5'-TCC AGG TGG CTT ATG GAG TC-3' \\
\hline
\end{tabular}




\section{Statistical analysis}

Data were examined for normality and analyzed using the GLM procedure (SAS Inst. Inc., Cary, NC). One-way analysis of variance model was used to test the data. When there was a significant main effect, separation of means was accomplished with the Tukey mean separation procedure. Differences were considered significant at $P<0.05$ and at $\mathrm{P}<0.10$ for tendency towards significance. Values in texts represent means \pm SEM.

\section{Results}

\section{Fatty acid composition and animal performance}

The fatty acid composition of experimental oils is presented in Table 2. The SBO has a linoleic acid and $\alpha-$ linolenic acid content of 54.8 and $7.5 \%$ respectively. The LLO has a content of 60.1 and $1.5 \%$ linoleic acid and $\alpha$ linloenic acids respectively. The fatty acid composition of experimental diets is presented in Table 3. The CON, SBO and LLO diets have a linoleic acid content of 45.51, 53.59 and $56.90 \%$ respectively. The content of $\alpha$-linolenic in the diets was $3.68,7.14$ and $1.95 \%$ for the CON, SBO and LLO diets respectively. The daily feed intakes across treatments were $1.55,1.19$ and $1.16 \mathrm{~kg} /$ day for the CON, SBO and LLO diets, respectively, and these were not different statistically. Estimated mean daily energy intakes were $4697.8,5533.5$ and $5394.0 \mathrm{kcal} /$ day for the CON, SBO and LLO diets, respectively. However, because of the higher proportion of fat in the high fat diets (Table 1), estimated daily fat calories consumed in the diets were 512.1, 2263.2 and $2206.2 \mathrm{kcal} /$ day for the CON, SBO and LLO diets, respectively. Total energy and fat calorie intake were similar in the SBO and LLO treatments, but higher than the CON. Although pigs were allowed to eat ad libitum, the total energy intake in the SBO and LLO diets was approximately $17 \%$ higher than in the $\mathrm{CON}$ diet. However, the fat calorie intake was 336\% higher in the SBO and LLO diets than the $\mathrm{CON}$ diet. As expected, the differences in fat calories and the quantities of individual fatty acids consumed indicate that these were the main determinants of responses obtained in the diets. The estimated daily intake of fatty acids is presented in Table 5. The intake of linoleic acid in the CON, SBO and LLO diets were 27.51, 125.62 and $130.03 \mathrm{~g} /$ day. The intake of $\alpha$-linolenic acid was $2.23,16.73$ and 4.46 for the CON, SBO and LLO diets respectively. The n6:n3 fatty acid intake ratios were 12.36, 7.54 and 29.20 for the CON, SBO and LLO diets respectively. Final mean body weights were 38.3, 40.3 and $39.3 \mathrm{~kg}$ for the CON, SBO and LLO treatments, respectively, and these were not significantly different.

\section{Serum metabolite profile}

The serum concentration of selected metabolites is presented in Table 6. Although the SBO diet resulted in
Table 5 Estimated daily fatty acid intake per pig

\begin{tabular}{|c|c|c|c|}
\hline \multirow[t]{2}{*}{ Fatty acid (g/d) } & \multicolumn{3}{|c|}{ Treatment $^{1}$} \\
\hline & CON & SBO & LLO \\
\hline Myristic acid & 0.18 & 0.19 & 0.23 \\
\hline Palmitic acid & 8.51 & 25.62 & 24.11 \\
\hline Palmitoleic acid & 0.18 & 0.24 & 0.29 \\
\hline$\underline{\text { Stearic acid }}$ & 2.72 & 9.25 & 10.60 \\
\hline Oleic acid & 13.27 & 46.20 & 48.61 \\
\hline Vaccenic acid & 0.71 & 3.05 & 2.85 \\
\hline Linoleic acid & 27.51 & 125.62 & 130.03 \\
\hline cis9, trans $11 \mathrm{CLA}$ & ND & 0.53 & 0.20 \\
\hline trans 10 , cis $12 \mathrm{CLA}$ & ND & ND & ND \\
\hline a-Linolenic acid & 2.23 & 16.73 & 4.46 \\
\hline Arachidonic acid & ND & ND & ND \\
\hline Eicosapentaenoic acid & ND & ND & ND \\
\hline Docosahexaenoic acid & ND & ND & ND \\
\hline Omega 6 (n6) & 27.51 & 126.16 & 130.22 \\
\hline Omega 3 (n3) & 2.23 & 16.73 & 4.46 \\
\hline Omega 6: Omega 3 (n6/n3) & 12.36 & 7.54 & 29.20 \\
\hline
\end{tabular}

${ }^{1}$ CON, control diet with no added oil; SBO, metabolic syndrome diet + 13\% soybean oil; LLO, metabolic syndrome diet $+13 \%$ low a-linolenic soybean oil. ${ }^{2} \mathrm{ND}$ - not detected.

marginal increase in the serum glucose concentration relative to the $\mathrm{CON}$ diet, it resulted in a significant increase serum insulin concentration. The LLO diet had a lower concentration of both glucose and insulin than the $\mathrm{CON}$ and SBO diets $(\mathrm{P}<0.05)$. However, the SBO and LLO groups had higher serum non-esterified fatty acids (NEFA) concentration than the CON group $(\mathrm{P}<0.05)$. Serum triglyceride concentration was higher in the SBO group compared to LLO and CON groups $(\mathrm{P}<0.05)$.

Table 6 Effect of diets on serum metabolites

\begin{tabular}{|c|c|c|c|c|}
\hline \multirow{2}{*}{ Variable } & \multicolumn{4}{|c|}{ Treatment $^{1}$} \\
\hline & CON & SBO & LLO & SEM \\
\hline Free fatty acids (mmol/L) & $0.17^{c}$ & $0.28^{b}$ & $0.32^{a}$ & 0.01 \\
\hline Glucose (mmol/L) & $8.8^{b}$ & $9.7^{a}$ & $7.8^{c}$ & 0.7 \\
\hline Insulin (pmol/L) & $6.9^{b}$ & $30.9^{a}$ & $1.7^{c}$ & 0.7 \\
\hline Glucose: Insulin & $1.28^{\mathrm{b}}$ & $0.31^{c}$ & $4.59^{a}$ & 1.22 \\
\hline Triglycerides (mmol/L) & $0.5^{c}$ & $1.5^{\mathrm{a}}$ & $1.0^{b}$ & 0.03 \\
\hline C-reactive protein (mg/L) & $101.4^{a}$ & $45.8^{b}$ & $65.3^{b}$ & 8.2 \\
\hline Total Cholesterol (mmol/L) & $1.2^{b}$ & $4.9^{a}$ & $1.1^{b}$ & 0.08 \\
\hline HDL Cholesterol (mmol/L) & $0.31^{a}$ & $0.14^{b}$ & $0.25^{a b}$ & 0.03 \\
\hline LDL Cholesterol (mmol/L) & $0.8^{b}$ & $4.7^{a}$ & $0.9^{b}$ & 0.05 \\
\hline \multicolumn{5}{|c|}{$\begin{array}{l}{ }^{1} \text { Data are given as means and pooled SEM, } n=4 \text { per treatment group unless } \\
\text { noted otherwise. CON, control diet with no added oil; SBO, metabolic } \\
\text { syndrome diet }+13 \% \text { soybean oil; LLO, metabolic syndrome diet }+13 \% \text { low } \\
\text { a-linolenic soybean oil. a,b,c Labeled means in a row without a common } \\
\text { superscript letter, } P<0.05 \text {. } \\
\text { HDL, high density lipoprotein; LDL, low density lipoprotein. }\end{array}$} \\
\hline
\end{tabular}


Total and LDL cholesterol concentrations were higher in the SBO group than in the CON and SBO groups. However, serum C-reactive protein (CRP) concentration was lower in the SBO and LLO diets than CON diet $(\mathrm{P}<0.05)$.

\section{Serum and tissue fatty acid profile}

Serum and adipose tissue fatty acid composition are presented in Tables 7 and 8 respectively. The content of SFA was higher in the serum from CON group that the SBO and LLO groups $(\mathrm{P}<0.05)$ (Table 7$)$. Furthermore, the SBO group had a higher content of mono unsaturated fatty acids (MUFA), but a lower content of polyunsaturated fatty acids (PUFA) in the serum (Table 7) and subcutaneous fat tissue (Table 8), than the CON and LLO groups. Pigs in the SBO group had a higher MUFA: SFA ratio, but PUFA: SFA ratio was higher in the serum (Table 7) and subcutaneous fat tissue (Table 8) of pigs on the LLO diet. Additionally, pigs fed the SBO diet had a higher serum and subcutaneous fat tissue $\alpha$-linolenic

Table 7 Effect of diets on serum fatty acid profile

\begin{tabular}{|c|c|c|c|c|}
\hline \multirow[t]{2}{*}{ Fatty acid (\%) } & \multicolumn{3}{|c|}{ Treatment $^{1}$} & \multirow[b]{2}{*}{ SEM } \\
\hline & CON & SBO & LLO & \\
\hline Myristic acid & $1.1^{\mathrm{b}}$ & $3.5^{\mathrm{a}}$ & $1.0^{c}$ & 0.01 \\
\hline Palmitic acid & $23.1^{a}$ & $20.2^{b}$ & $19.3^{c}$ & 0.07 \\
\hline Palmitoleic acid & $1.25^{\mathrm{C}}$ & $1.60^{a}$ & $1.18^{\mathrm{b}}$ & 0.01 \\
\hline Stearic acid & $15.8^{a}$ & $12.0^{b}$ & $11.9^{c}$ & 0.03 \\
\hline Oleic acid & $35.4^{b}$ & $38.8^{a}$ & $31.5^{c}$ & 0.06 \\
\hline Vaccenic acid & $1.9^{c}$ & $2.7^{\mathrm{a}}$ & $1.9^{b}$ & 0.01 \\
\hline Linoleic acid & $14.3^{b}$ & $11.8^{c}$ & $25.8^{a}$ & 0.02 \\
\hline cis9, trans11 CLA & $1.0^{\mathrm{b}}$ & $0.9^{c}$ & $1.2^{a}$ & 0.02 \\
\hline trans10, cis 12 CLA & $0.04^{\mathrm{ab}}$ & $0.05^{a}$ & $0.04^{b}$ & 0.004 \\
\hline a-Linolenic acid & $0.1^{\mathrm{b}}$ & $0.8^{a}$ & $0.1^{b}$ & 0.01 \\
\hline Arachidonic acid & $1.0^{\mathrm{b}}$ & $0.6^{c}$ & $1.3^{\mathrm{a}}$ & 0.01 \\
\hline Eicosapentaenoic acid & $0.24^{a}$ & $0.16^{c}$ & $0.22^{b}$ & 0.01 \\
\hline Docosahexaenoic acid & $0.16^{a}$ & $0.13^{b}$ & $0.15^{\mathrm{ab}}$ & 0.01 \\
\hline Omega 6 (n6) & $15.5^{b}$ & $12.6^{c}$ & $27.2^{a}$ & 0.02 \\
\hline Omega 3 (n3) & $0.8^{\mathrm{b}}$ & $1.4^{\mathrm{a}}$ & $0.7^{c}$ & 0.02 \\
\hline Omega 6: Omega3 (n6/n3) & $19.8^{b}$ & $9.3^{c}$ & $39.1^{a}$ & 0.7 \\
\hline Total SFA ${ }^{2}$ & $40.0^{a}$ & $35.6^{b}$ & $32.1^{c}$ & 0.07 \\
\hline Total MUFA ${ }^{3}$ & $39.6^{b}$ & $44.1^{a}$ & $35.5^{c}$ & 0.06 \\
\hline Total PUFA & $17.7^{b}$ & $15.2^{c}$ & $29.6^{a}$ & 0.03 \\
\hline MUFA: SFA & $1.02^{c}$ & $1.24^{\mathrm{a}}$ & $1.11^{\mathrm{b}}$ & 0.003 \\
\hline PUFA: SFA & $0.44^{b}$ & $0.43^{c}$ & $0.94^{a}$ & 0.001 \\
\hline
\end{tabular}

${ }^{1}$ Data are given as means and pooled SEM, $n=4$ per treatment group unless noted otherwise. CON, control diet with no added oil; SBO, metabolic

syndrome diet $+13 \%$ soybean oil; LLO, metabolic syndrome diet $+13 \%$ low alinolenic soybean oil. ${ }^{a, b}, c$ Labeled means in a row without a common

superscript letter, $\mathrm{P}<0.05$.

2 SFA- saturated fatty acid.

${ }^{3}$ MUFA - Mono unsaturated fatty acid.

${ }^{4}$ PUFA- Poly unsaturated fatty acid.
Table 8 Effect of diets on subcutaneous fat fatty acid profile

\begin{tabular}{|c|c|c|c|c|}
\hline \multirow[t]{2}{*}{ Fatty acid (\%) } & \multicolumn{3}{|c|}{ Treatment $^{1}$} & \multirow[b]{2}{*}{ SEM } \\
\hline & CON & SBO & LLO & \\
\hline Myristic acid & $1.1^{\mathrm{b}}$ & $3.3^{a}$ & $0.8^{c}$ & 0.02 \\
\hline Palmitic acid & $23.3^{a}$ & $20.2^{b}$ & $18.3^{c}$ & 0.05 \\
\hline Palmitoleic acid & $1.3^{b}$ & $1.6^{a}$ & $1.0^{c}$ & 0.004 \\
\hline Stearic acid & $15.5^{a}$ & $12.5^{\mathrm{b}}$ & $12.5^{b}$ & 0.04 \\
\hline Oleic acid & $36.4^{b}$ & $39.2^{a}$ & $32.1^{c}$ & 0.12 \\
\hline Vaccenic acid & $2.0^{\mathrm{b}}$ & $2.8^{\mathrm{a}}$ & $1.8^{c}$ & 0.01 \\
\hline Linoleic acid & $14.2^{b}$ & $11.6^{c}$ & $27.5^{\mathrm{a}}$ & 0.05 \\
\hline cis9, trans $11 \mathrm{CLA}$ & $1.0^{\mathrm{b}}$ & $0.8^{c}$ & $1.2^{\mathrm{a}}$ & 0.01 \\
\hline trans 10 , cis $12 \mathrm{CLA}$ & $0.34^{a}$ & $0.26^{c}$ & $0.28^{\mathrm{b}}$ & 0.003 \\
\hline a-Linolenic acid & $0.05^{c}$ & $0.80^{\mathrm{a}}$ & $0.09^{b}$ & 0.004 \\
\hline Arachidonic acid & $1.0^{\mathrm{b}}$ & $0.6^{c}$ & $1.4^{\mathrm{a}}$ & 0.01 \\
\hline Eicosapentaenoic acid & $0.23^{a}$ & $0.15^{c}$ & $0.22^{b}$ & 0.001 \\
\hline Docosahexaenoic acid & $0.14^{a}$ & $0.10^{\mathrm{b}}$ & $0.14^{\mathrm{a}}$ & 0.004 \\
\hline Omega 6 (n6) & $15.3^{b}$ & $12.4^{c}$ & $28.9^{\mathrm{a}}$ & 0.04 \\
\hline Omega 3 (n3) & $0.42^{c}$ & $1.05^{\mathrm{a}}$ & $0.45^{\mathrm{b}}$ & 0.004 \\
\hline Omega 6: Omega 3 (n6/n3) & $37.2^{\mathrm{b}}$ & $11.8^{c}$ & $65.3^{\mathrm{a}}$ & 0.26 \\
\hline Total SFA ${ }^{2}$ & $40.1^{a}$ & $36.0^{b}$ & $31.7^{c}$ & 0.06 \\
\hline Total MUFA ${ }^{3}$ & $41.0^{\mathrm{b}}$ & $44.6^{a}$ & $35.9^{c}$ & 0.13 \\
\hline Total PUFA & $17.5^{\mathrm{b}}$ & $14.8^{c}$ & $31.3^{\mathrm{a}}$ & 0.043 \\
\hline MUFA: SFA & $1.03^{c}$ & $1.24^{\mathrm{a}}$ & $1.16^{\mathrm{b}}$ & 0.003 \\
\hline PUFA: SFA & $0.44^{\mathrm{b}}$ & $0.41^{c}$ & $1.06^{\mathrm{a}}$ & 0.001 \\
\hline
\end{tabular}

${ }^{1}$ Data are given as means and pooled SEM, $n=4$ per treatment group unless noted otherwise. CON, control diet with no added oil; SBO, metabolic syndrome diet $+13 \%$ soybean oil; LLO, metabolic syndrome diet $+13 \%$ low alinolenic soybean oil. ${ }^{\mathrm{a}, \mathrm{b}, \mathrm{c}}$ Labeled means in a row without a common superscript letter, $\mathrm{P}<0.05$.

2 SFA- saturated fatty acid.

${ }^{3}$ MUFA - Mono unsaturated fatty acid.

${ }^{4}$ PUFA- Poly unsaturated fatty acid.

and oleic acid content. Serum and subcutaneous fat tissue linoleic acid content was also higher in the LLO group compared to the $\mathrm{CON}$ and SBO groups. However, stearic acid content was higher in both the serum and subcutaneous fat tissue of pigs on the CON diet than in those on the SBO and LLO diets. Trans10, cis12 CLA content was higher in the subcutaneous fat tissue of pigs in the CON group than in those in the SBO and LLO groups. However, cis 9, trans11 CLA content was higher in the subcutaneous fat tissue of pigs in the LLO group compared to those in the CON and SBO groups.

Inflammatory and extracellular matrix gene expression in adipose tissue

Expression of extracellular matrix and inflammatory genes was also determined. The expression of Col1A was lower in SBO group compared to LLO and CON groups $(\mathrm{P}<0.05)$. There was also a tendency $(\mathrm{P}<0.1)$ for 
a lower expression of COLVIA and fibronectin in the SBO treatment than the CON and LLO treatments (Table 9). However, expression of two inflammatory markers, MCP-1 and CD68 was not different in the subcutaneous tissue in the different dietary groups $(\mathrm{P}>0.05)$ (Table 9). To determine the association fatty acid profile in the serum and adipose tissue and serum metabolite profile, a correlation analysis was conducted between these variables. Serum CRP was the only serum variable that was negatively correlated only to MUFA: SFA ratio $(\mathrm{r}=-0.53 ; \mathrm{P}<0.07)$. Correlation to individual fatty acids was weak $(P>0.1)$. The MUFA: SFA ratio was higher in both SBO and LLO diets and these diets had lower serum CRP concentration (Table 6). This suggests that the overall fatty acid profile and the sum of action of individual fatty acids may be very important in determining the metabolic response to the diets.

\section{Adiponectin expression}

Western blot analysis of adiponectin protein in the subcutaneous adipose tissue is presented in Figure 1. Higher expression of adiponectin protein was observed in pigs on the SBO diet compared to those on the CON diet $(\mathrm{P}<0.05)$. However, similar levels were observed between the SBO and LLO groups.

\section{Discussion}

Several advantages are associated with the use of the pig as a model for human nutrition research. These include its similar organ sizes compared to humans [14], similar digestive tract architecture, and similar lipid and carbohydrate metabolism [15-17]. Additionally, the Ossabaw pig is an excellent model for the study of metabolic syndrome as this animal model easily develops dyslipidemia when fed a diet high in fatty acids and cholesterol $[18,19]$. Consumption of a high fat, high calorie diet is

Table 9 Expression of inflammatory and extracellular matrix genes in subcutaneous adipose tissue

\begin{tabular}{lccccc}
\hline \multirow{2}{*}{ Genes } & \multicolumn{3}{c}{ Treatment $^{\mathbf{1}}$} & & \begin{tabular}{c} 
P \\
\cline { 2 - 4 }
\end{tabular} \\
\cline { 2 - 5 } CON & SBO & LLO & SEM & value \\
\hline TNFa & $0.870^{\mathrm{b}}$ & $1.073^{\mathrm{ab}}$ & $1.667^{\mathrm{a}}$ & 0.229 & 0.05 \\
\hline IL-6 & $0.571^{\mathrm{b}}$ & $1.705^{\mathrm{a}}$ & $1.350^{\mathrm{a}}$ & 0.212 & 0.05 \\
\hline Adiponectin & $0.541^{\mathrm{b}}$ & $1.055^{\mathrm{a}}$ & $0.914^{\mathrm{ab}}$ & 0.14 & 0.05 \\
\hline Col1A & $1.681^{\mathrm{a}}$ & $0.482^{\mathrm{b}}$ & $1.733^{\mathrm{a}}$ & 0.225 & 0.05 \\
\hline ColVIA & 1.243 & 0.760 & 1.438 & 0.237 & 0.10 \\
\hline Fibronectin & 1.363 & 0.701 & 1.390 & 0.232 & 0.10 \\
\hline CD68 & 1.243 & 0.885 & 1.373 & 0.254 & 0.10 \\
\hline MCP-1 & 0.872 & 1.256 & 1.247 & 0.198 & 0.10
\end{tabular}

${ }^{1}$ Data are given as means and pooled SEM, $n=4$ per treatment group. CON, control diet with no added oil; SBO, metabolic syndrome diet $+13 \%$ soybean oil; LLO, metabolic syndrome diet $+13 \%$ low a-linolenic soybean oil. ${ }^{\mathrm{a}, \mathrm{b}}$ Labeled means in a row without a common superscript letter differ, $\mathrm{P}<0.05$.

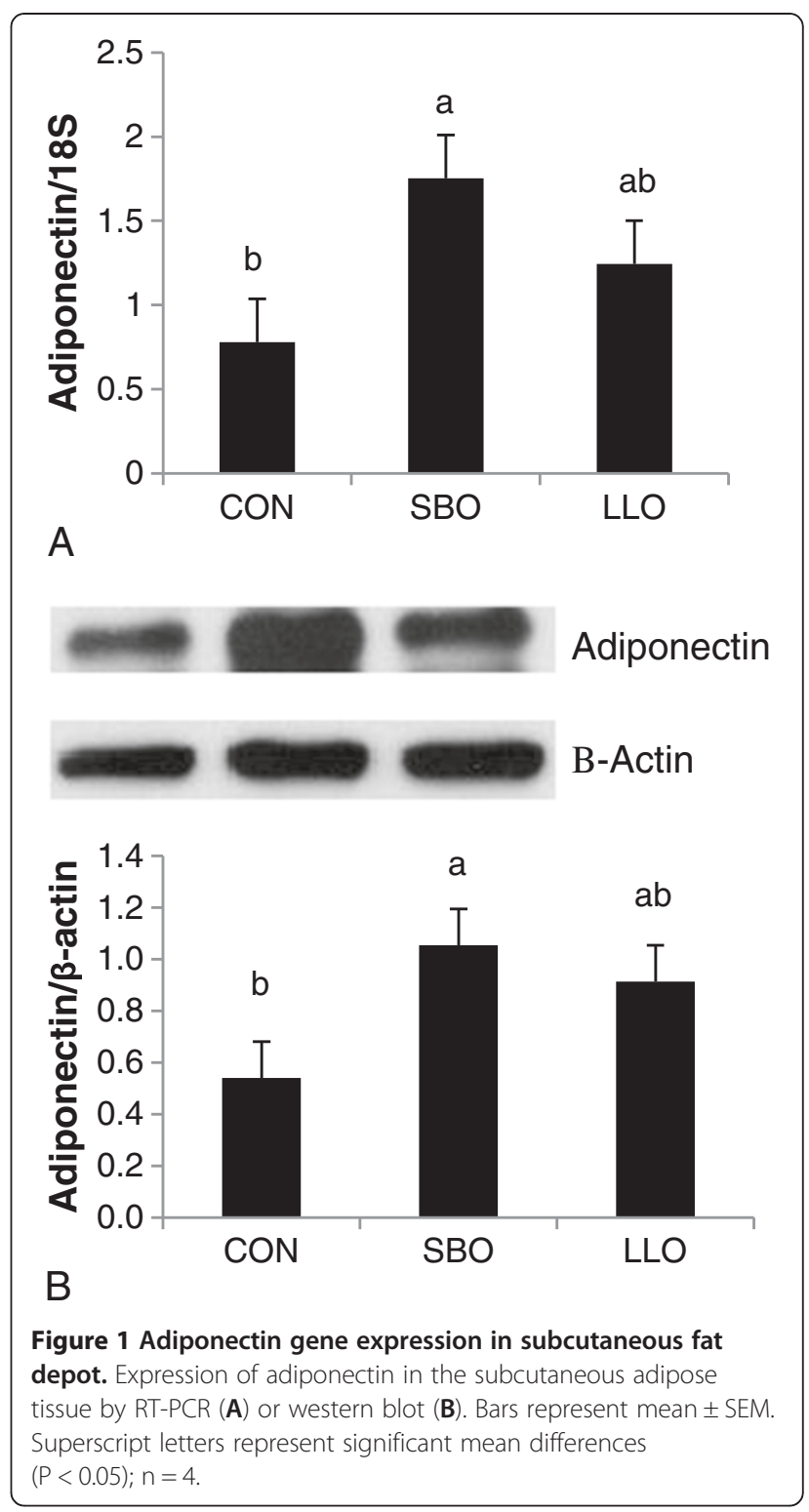

also associated with increased risk of obesity, diabetes and cardiovascular disease $[1,3]$. Soy oil is a major vegetable oil consumed in the US [6]. It is rich in PUFAs which are highly susceptible to oxidative damage. Therefore, soy oil is usually hydrogenated to increase the shelf life of products made from it, a process that results in generation of trans fatty acids.

Consumption of high amounts of trans fat is linked to increased risk of cardiovascular diseases [20]. Lowering the content of $\alpha$-linolenic acid to reduce soy oil unsaturation is a strategy for eliminating the need for soy oil hydrogenation and improving the shelf life of food products containing soy oil. Although this approach lowers the degree of unsaturation of soy oil, it increases its $(n-6) /(n-3)$ ratio and the implications of long-term consumption of this oil on metabolic status are unknown. There has been 
no systematic study to characterize the metabolic response to consumption of the low $\alpha$-linolenic compared to the standard soy oil. We report herein a comparison of several metabolic responses that may be associated with human consumption of the two types of soy oil using the pig model.

The estimated daily intakes of linoleic and $\alpha$-linolenic acid in all treatments groups far exceeded the estimated daily intake for humans which ranged from 10.4-14.7 g/d for linoleic acid and 1.1-1.6 g/d for $\alpha$-linolenic acid [21]. A major reason for this difference is the much larger feed intake in pigs relative to humans and the difference in feed composition between pigs and humans in general. The pig diet is also different from typical human diet due the absence of long chain PUFA such as eicosapentaenoic acid (EPA) and docosahexaenoic acid (DHA). The n6:n3 ratios of 12.36 and 7.54 in the control and SBO diets are not too far off from the 10.6:1 ratio in human diets [22]. However the ratio of 29.2 consumed in the LLO diet is quite different from human diet and far from the recommended n6:n3 of 4.0 in human diets [23]. The higher dietary n6:n3 ratio in the LLO diets is further reflected in the elevation of this ratio in the serum and subcutaneous adipose tissue as well. This underscores the disruption that may occur to this ratio in serum and adipose tissue if low $\alpha$-linolenic acid represents a major source of n3 fatty acids in human diets. Because insulin resistant state if often marked by elevated serum insulin and glucose concentrations [24,25], the elevated glucose and insulin concentrations in the SBO diet relative to the CON and LLO diets could suggest development of insulin resistance in pigs on this treatment, and indicate that the LLO oil prevents pigs from developing insulin resistance, despite consuming similar level of dietary fat as in the SBO diet. Likewise, the higher levels of triglycerides, LDL-cholesterol and the lower level of HDL-cholesterol in pigs on the SBO diet may point to development of dyslipidemia, a condition that is marked by elevated levels of blood lipids [26]. Thus consumption of LLO oil may offer some protection against development of both insulin resistance and dyslipidemia. Therefore, the disruption of the n6:n3 ratio in the LLO did not result in a significant adverse metabolic response. Consumption of both SBO and LLO diets resulted in a lower level of CRP than in pigs on the CON diet. CRP is a cardiovascular disease marker [27]. The reduction in CRP concentration in the SBO and LLO diets is consistent with the reported effect of PUFA in reducing CRP concentration $[28,29]$ and indicates that despite the reduced content of $\alpha$-linolenic acid, the low $\alpha$ - linolenic oil was effective in lowering the concentration of this cardiovascular disease marker and this might indicate that $\alpha$-linolenic acid may not be the major factor in soy oil regulating the concentration of CRP. Soy is rich in linoleic acid, and due to its anti-inflammatory property, this fatty acid could be the major player in lowering the concentration of CRP $[28,29]$.

Several distinct differences in the serum fatty acid profiles between pigs on the SBO and LLO diets could explain the different serum metabolic profile in the pigs. The LLO diet resulted in higher cis 9, trans 11 CLA, reduced total SFA, increased total PUFA content and higher PUFA: SFA ratio in the serum than the SBO diet. It has been reported previously that dietary inclusion of cis 9, trans 11 CLA in mice led to improved glucose tolerance, insulin sensitivity and reduction in triacylglycerol content compared to control fed mice [30,31]. Choi et al. [32] showed a higher response to insulin in rats whose diets were supplemented with CLA. Furthermore, inclusion of cis 9, trans 11 CLA in ob/ob mice improved insulin signaling [31]. SFAs have been shown to impair insulin signaling [33] whereas PUFAs enhance it [34]. Therefore, the overall changes in the fatty acid profile in the LLO treatment may support enhanced insulin sensitivity in vivo. Increased insulin sensitivity will also result in reduced serum cholesterol concentration [35]. This is in agreement with the reduced serum cholesterol content in the serum of LLO pigs observed in this study. As found earlier [36], consumption of cis 9, trans 11 CLA by ApoE knockout mice resulted in reduced triglycerides, improved glucose tolerance and insulin sensitivity compared to control fed mice. Thus cis 9, trans11 CLA may have played a big role in the apparent enhanced insulin sensitivity in the LLO diet. Finally, the lower SFA, higher PUFA content and higher PUFA: SFA ratio in the LLO fed pigs could have contributed to their improved metabolic profile as well. Consumption of lower amounts of SFA and consumption of higher amounts of PUFA are both associated with reduction in risks for development of inflammation and metabolic syndrome [37-39]. Although associations between consumption of individual fatty acids and serum metabolites are well established [28-39], it is probable that the overall fatty acid profile and the complex interactions it engenders between individual components may play important roles in determining the dietary effects observed. A comprehensive metabolomics analysis may be needed in the future for such a determination. Obesity is currently regarded as low-grade chronic inflammatory disease [40] and consumption of $\mathrm{n} 3$ fatty acid enriched diets may offer protection against obesity-induced inflammation [41]. In this study consumption of both SBO and LLO diets resulted in elevated adipose tissue expression of IL-6. However, the higher expression of TNF $\alpha$ in the adipose tissue of pigs on the LLO diet than those on the CON diet may suggest a potential loss of some antiinflammatory effects of ALA in the LLO diet and this could be a disadvantage of consuming a diet low in ALA. Nevertheless, the overall limited effect of reducing 
ALA level in the diet of pigs on the LLO diet may suggest a weak link between ALA and the regulation of inflammation. Indeed, in healthy human subjects with large waist circumferences, increased ALA consumption from flaxseed oil consumption failed to reduce inflammatory makers [42]. Therefore, the importance of ALA consumption in regulating adipose tissue inflammation could be complex and additional studies are required to further elucidate the importance of ALA in the regulation of inflammation.

Adiponectin is an adipocyte-derived hormone that can improve insulin sensitivity by regulating glucose utilization and fatty acid metabolism. It is possible that the elevated serum and subcutaneous adipose tissue adiponectin abundance in the SBO group is related to the elevated oleic acid abundance in the serum and subcutaneous adipose tissue of pigs in this group. In support of this hypothesis, a recent study by Granados et al. [43] showed that incubation of 3T3-L1 adipocytes with oleic acid increased adiponectin mRNA levels. Positive association between adipose tissue oleic acid content and serum adiponectin concentration has also been reported [44]. Therefore, elevated oleic acid level in the serum and adipose tissue of SBO pigs may partly contribute to the higher expression of adiponectin in this treatment.

In summary, we report herein that feeding the low $\alpha$ linolenic soy oil resulted in alteration of serum metabolite profile marked by reduced serum glucose, insulin, triglycerides and total and LDL cholesterol concentrations compared to regular soy oil. However, there were no significant changes in the expression of inflammatory markers. We speculate that these changes may be driven by the reduction in SFA content, elevation of PUFA and cis 9, trans 11 CLA content and the increase in PUFA: SFA ratio following consumption of the LLO diet.

\section{Competing interests}

The authors declare no conflict of interest.

\section{Authors' contributions}

RBP, OA and KMA designed the research. RBP, HL and KMA conducted the research. RBP and KMA analyzed the data. RBP, HL and KMA wrote the paper. KMA had primary responsibility for the final content. All authors read and approved the final manuscript.

\section{Acknowlegements}

The authors wish to acknowledge help from Mike Sturek, Indiana University School of Medicine, in sourcing pigs used for this study and Michelle Chia-Li Shih and Jason Fields for providing animal handling support. Indiana Soybean Alliance provided partial funding for this work.

Received: 29 January 2013 Accepted: 7 March 2013

Published: 14 March 2013

\section{References}

1. Murtaugh MA, Herrick JS, Sweeney C, Baumgartner KB, Guiliano AR, Byers T, Slattery ML: Diet composition and risk of overweight and obesity in women living in the southwestern United States. J Am Diet Assoc 2007, 107:1311-1321.
2. Ahluwalia N, Ferrieres J, Dallongeville J, Simon C, Ducimetiere P, Amouyel P, Arveiler D, Ruidavets JB: Association of macronutrient intake patterns with being overweight in a population-based random sample of men in France. Diabetes Metab 2009, 35:129-136.

3. Drewnowski A: Obesity, diets, and social inequalities. Nutr Rev 2009, 67:S36-S39.

4. Buettner R, Scholmerich J, Bollheimer LC: High-fat diets: modeling the metabolic disorders of human obesity in rodents. Obesity 2007, 15:798-808.

5. Siri-Tarino PW, Sun Q, Hu FB, Krauss RM: Saturated fat, carbohydrate, and cardiovascular disease. Am J Clin Nutr 2010, 91:502-509.

6. Zhao G, Etherton TD, Martin KR, West SG, Gillies PJ, Kris-Etherton PM: Dietary alpha-linolenic acid reduces inflammatory and lipid cardiovascular risk factors in hypercholesterolemic men and women. J Nutr 2004, 134:2991-2997.

7. Donald BJ, Depner CM, Tripathy S: Omega-3 fatty acid supplementation and cardiovascular disease. $J$ of Lipid research 2012, 53:2525-2545.

8. Connor W: Importance of $\mathrm{n}-3$ fatty acids in health and disease. Am J Clin Nutr 2000, 71:S171-S175

9. Blasbalg TL, Hibbeln JR, Ramsden CE, Majchrzak SF, Rawlings RR: Changes in consumption of omega- 3 and omega- 6 fatty acids in the United States during the 20th century. Am J Clin Nutr 2011, 93:950-962.

10. Wilson RF: Seed composition. In Soybeans: improvement, production, and uses. Edited by Boerma HR, Specht JE. Madison: American Society of Agronomy, Inc., Crop Science Society of America, Inc., Soil Science Society of America, Inc; 2004:621-677.

11. Slavin M, Cheng Z, Luther M, Kenworthy W, Yu L: Antioxidant properties and phenolic, isoflavone, tocopherol, and carotenoid composition of Maryland-grown soybean lines with altered fatty acid profiles. Food Chem 2009, 114:20-27.

12. Pfaffl MW: A new mathematical model for relative quantification in realtime RT-PCR. Nucleic Acids Res 2001, 29:e45.

13. Folch J, Lees M, Sloane Stanley GH: A simple method for the isolation and purification of total lipids from animal tissues. J Biol Chem 1957, 226:497-509.

14. Miller ER, Ullrey DE: The pig as a model for human nutrition. Annu Rev Nutr 1987, 7:361-382.

15. Rowan AM, Moughan PJ, Wilson MN: Comparison of the ileal and fecal digestibility of dietary amino acids in adult humans and evaluation of the pig as a model animal for digestion studies in man. Br J Nutr 1994, 71:29-42.

16. Spurlock ME, Gabler NK: The development of porcine models of obesity and the metabolic syndrome. J Nutr 2008, 138:397-402.

17. Deglaire A, Bos C, Tome D, Moughan PJ: lleal digestibility of dietary protein in the growing pig and adult human. Br J Nutr 2009, 102:1752-1759.

18. Dyson MC, Alloosh M, Vuchetich JP, Mokelke EA, Sturek M: Components of metabolic syndrome and coronary artery disease in female Ossabaw swine fed excess atherogenic diet. Comp Med 2006, 56:35-45.

19. Lee L, Alloosh M, Saxena R, Van Alstine W, Watkins BA, Klaunig JE, Sturek M, Chalasani N: Nutritional model of steatohepatitis and metabolic syndrome in the Ossabaw miniature swine. Hepatology 2009, 50:56-67.

20. Eckel R, Borra S, Lichtenstein A, Yin-Piazza S: Understanding the complexity of trans fatty acid reduction in the American diet: American Heart Association Trans Fat Conference 2006: report of the Trans Fat Conference Planning Group. Circulation 2007, 115:2231-2245.

21. Jonnalagadda SS, Egan SK, Heimbach JT, Harris SS, Kris-Etherton PM: Fatty acid consumption pattern of Americans: 1987-1988 USDA Nationwide Food Consumption Survey. Nutr Res 1995, 15:1767-1781

22. Kris-Etherton PM, Taylor DS, Yu-Poth S, Huth P, Moriarty K, Fishell V, Hargrove RL, Zhao G, Etherton TD: Polyunsaturated fatty acids in the food chain in the United States. Am J Clin Nutr 2000, 71(1 Suppl):179S-188S.

23. Wood JD, Richardson RI, Nute GR, Fisher AV, Campo MM, Kasapidou E: Effects of fatty acids on meat quality: a review. Meat Sci 2003, 66:21-32.

24. Seppala-Lindroos A, Vehkavaara S, Hakkinen AM, Goto T, Westerbacka J, Sovijarvi A, Halavaara J, Yki-Jarvinen H: Fat accumulation in the liver is associated with defects in insulin suppression of glucose production and serum free fatty acids independent of obesity in normal men. J Clin Endocrinol Metab 2002, 87:3023-3028.

25. Ryysy L, Hakkinen AM, Goto T, Vehkavaara S, Westerbacka J, Halavaara J, YkiJarvinen $\mathrm{H}$ : Hepatic fat content and insulin action on free fatty acids and glucose metabolism rather than insulin absorption are associated with insulin requirements during insulin therapy in type 2 diabetic patients. Diabetes 2000, 49:749-758. 
26. Goldberg RB, Kendall DM, Deeg MA, Buse JB, Zagar AJ, Pinaire JA, Tan MH, Khan MA, Perez AT, Jacober SJ: A comparison of lipid and glycemic effects of pioglitazone and rosiglitazone in patients with type 2 diabetes and dyslipidemia. Diabetes Care 2005, 28:1547-1554.

27. Hirofumi T, Matsumoto C, Odaira M, Yamada J, Yoshida M, Shiina K, Nagata $M$, Yamashina A: Relationships among the serum omega fatty acid levels, serum C-reactive protein levels and arterial stiffness/wave reflection in Japanese men. Atherosclerosis 2011, 217:433-436.

28. Lopez-Garcia E, Schulze MB, Manson JE: Consumption of (n-3) fatty acids is related to plasma biomarkers of inflammation and endothelial activation in women. J Nutr 2004, 134:1806-1811.

29. Poudel-Tandukar K, Nanri A, Matsushita Y, Sasaki S, Ohta M, Sato M, Mizoue $\mathrm{T}$ : Dietary intakes of $a$-linolenic acid and linoleic acids are inversely associated with serum C-reactive protein levels among Japanese men. Nutr Res 2009, 29:363-370.

30. Kelley DS, Bartolini GL, Warren JM, Simon VA, Mackey BE, Erickson KL: Contrasting effects of $\mathrm{t} 10, \mathrm{c} 12$ - and $\mathrm{c} 9, \mathrm{t} 11$-conjugated linoleic acid isomers on the fatty acid profiles of mouse liver lipids. Lipids 2004, 39:135-141.

31. Moloney F, Toomey S, Noone E, Nugent A, Allan B, Loscher CE, Roche HM: Antidiabetic effects of cis-9, trans-11-conjugated linoleic acid may be mediated via anti-inflammatory effects in white adipose tissue. Diabetes 2007, 56:574-582.

32. Choi JS, Koh IU, Jung MH, Song J: Effects of three different conjugated linoleic acid preparations on insulin signalling, fat oxidation and mitochondrial function in rats fed a high-fat diet. Br J Nutr 2007, 98:264-275.

33. Kennedy A, Martinez K, Chuang CC, LaPoint K, McIntosh M: Saturated fatty acid mediated inflammation and insulin resistance in adipose tissue mechanisms of action and implications. J Nutr 2009, 139:1-4.

34. Summers LK, Fielding BA, Bradshaw HA, Ilic V, Beysen C, Clark ML, Moore NR, Frayn KN: Substituting dietary saturated fat with polyunsaturated fat changes abdominal fat distribution and improves insulin sensitivity. Diabetologia 2002, 45:369-377.

35. Mooradian AD: Dyslipidemia in type 2 diabetes mellitus. Nat Clin Pract Endo Metab 2009, 5:150-159.

36. Roos BD, Rucklidge G, Reid M, Ross K, Duncan G, Navarro MA, ArbonesMainar JM, Guzman-Garcia MA, Osada J, Browne J, Loscher GE, Roche HM: Divergent mechanisms of cis9, trans11- and trans10, cis12-conjugated linoleic acid affecting insulin resistance and inflammation in apolipoprotein E knockout mice: a proteomics approach. FASEB 2005 19:1746-1748

37. Pischon T, Hankinson SE, Hotamisligil GS, Rifai N, Willett WC: Habitual dietary intake of $n-3$ and $n-6$ fatty acids in relation to inflammatory markers among US men and women. Circulation 2003, 108:155-160.

38. Ferrucci L, Cherubini A, Bandinelli S, Bartali B, Corsi A: Relationship of plasma polyunsaturated fatty acids to circulating inflammatory markers. J Clin Endo Metab 2006, 91:439-446.

39. Masson CJ, Mensink RP: Exchanging saturated fatty acids for (n-6) polyunsaturated fatty acids in a mixed meal may decrease postprandial lipemia and markers of inflammation and endothelial activity in overweight men. J Nutr 2011, 141:816-821.

40. Poitou C, Coussieu C, Rouault C, Coupaye M, Cancello R, Bedel JF: Serum amyloid A: a marker of adiposity-induced low-grade inflammation but not of metabolic status. Obesity 2006, 14:309-318.

41. Faintuch J, Horie LM, Barbeiro HV, Barbeiro DF, Soriano FG, Ishida RK Systemic inflammation in morbidly obese subjects: response to ora supplementation with alpha-linolenic acid. Obes Surg 2007, 17:341-347.

42. Nelson TL, Stevens JR, Hickey MS: Inflammatory markers are not altered by an eight week dietary alpha-linolenic acid intervention in healthy abdominally obese adult males and females. Cytokine 2007, 38:101-106.

43. Granados NAJ, Ribot J, Palou A, Bonet ML: Distinct effects of oleic acid and its trans-isomer elaidic acid on the expression of myokines and adipokines in cell models. Br J of Nut 2011, 105:1226-1234.

44. Perez de Heredia F, Sanchez J, Priego T: Adiponectin is associated with serum and adipose tissue fatty acid composition in rats. J Endo Invest 2009, 32:659-665.

doi:10.1186/1743-7075-10-27

Cite this article as: Potu et al:: Metabolic markers in Ossabaw pigs fed high fat diets enriched in regular or low a-linolenic acid soy oil. Nutrition \& Metabolism 2013 10:27

\section{Submit your next manuscript to BioMed Central and take full advantage of:}

- Convenient online submission

- Thorough peer review

- No space constraints or color figure charges

- Immediate publication on acceptance

- Inclusion in PubMed, CAS, Scopus and Google Scholar

- Research which is freely available for redistribution 